\title{
A Global and Hemispherical Analysis of the Lorenz Energetics Based on the Representative Concentration Pathways Used in CMIP5
}

\author{
José Augusto P. Veiga ${ }^{1,2}$ and Tercio Ambrizzi ${ }^{2}$ \\ ${ }^{1}$ Institute of Technology, Amazon State University, Avenue Darcy Vargas 1200, 69065-020 Manaus, AM, Brazil \\ ${ }^{2}$ Institute of Astronomy, Geophysics and Atmospheric Sciences, University of São Paulo, São Paulo, SP, Brazil \\ Correspondence should be addressed to José Augusto P. Veiga; veiga.uea@gmail.com
}

Received 18 April 2013; Revised 25 July 2013; Accepted 4 September 2013

Academic Editor: Klaus Dethloff

Copyright ( $\odot 2013$ J. A. P. Veiga and T. Ambrizzi. This is an open access article distributed under the Creative Commons Attribution License, which permits unrestricted use, distribution, and reproduction in any medium, provided the original work is properly cited.

So far, only a few studies have evaluated the impact of greenhouse gases emissions on the global and limited area energetics. Furthermore, all of them have concentrated on the increasing of $\mathrm{CO}_{2}$. As new climate projections are now available from a number of climate models under the MPI-ESR-MR experiment, the present study analyses the global and hemispherical energetics under the increase of greenhouse gas forcings that follow Representative Concentration Pathways (RCP26, RCP45, and RCP85). The results have shown a reduction in the $L E C$ intensity as the concentration of greenhouse gases increases, with the RCP85 scenario generating the strongest decrease. For both global and hemispherical domains, zonal kinetic energy is the only energy reservoir which increases in a warmer environment, whereas the conversion between eddy kinetic energy and zonal kinetic energy $\left(C_{K}\right)$ is the only energy flux also experiencing an increase. A quantitative analysis of the inner processes involved in the conversion terms shows important changes in the horizontal and vertical eddy-transport of momentum and sensible heat. In the case of $C_{K}$ both vertical and horizontal eddy-transports of momentum play an important role in the increase of zonal kinetic energy for the global domain.

\section{Introduction}

After Lorenz [1] has derived a set of equations to quantify the energy cycle for the whole atmosphere, many studies have applied the technique to quantify and understand the dynamical processes involved in the energetics of the planet (e.g., [2-9]) and those who are considering just a piece of the atmosphere (e.g., [10-19]). In particular, they differ from each other depending upon the purpose of use and the energetics formalism (space domain, time domain, and mixed space-time domain energetics, see [5]). As discussed in Lorenz [2] and Oort [4], although the absolute value produced by each technique differs from each other, the energy fluxes are qualitatively similar. In general, studies of energetics considering closed domain highlight the maintenance of the general circulation, while studies involving open domain stress the dynamics related to the life cycle of individual atmospheric disturbances.
The increasing of greenhouse gas emissions has amplified the greenhouse efficiency effect by trapping more heat in the mid- and lower troposphere and consequently altering the atmospheric circulation pattern [20]. The consequences of this can be felt through the changes in a broad spatial and temporal-scale of disturbances around both hemispheres as observed in the cases of cyclones and anticyclones (e.g., [21-27]), and tropical cyclones (e.g., [28-30]). For instance, based on a transient simulation run from ECHAM5/OM1 model, [27] revealed that there is a significantly increase in the frequency of the most severe storms over the eastern North Atlantic and North Pacific under an increasing of $\mathrm{CO}_{2}$ relative to the IPCC A1B scenario.

Reference [20] evaluated the atmospheric energetics in the North Hemisphere middle latitude relative to two $\mathrm{CO}_{2}$ concentration conditions $\left(1 \times \mathrm{CO}_{2}\right.$ and $\left.2 \times \mathrm{CO}_{2}\right)$ from a 10-year-numerical simulation with Canadian Centre for Climate Modelling and Analysis (CCCma) model. The results revealed a reduction in baroclinicity and baroclinic instability 
for the winter season in the case of doubled $\mathrm{CO}_{2}$ as a consequence of the modified temperature structure (decrease in pole to equator and land/ocean lower troposphere temperature gradients). Furthermore, the "rate of working" of the atmosphere, as characterized by the rate of generation of available potential energy and its conversion to kinetic energy and subsequent dissipation, is reduced in $12 \%$ relative to $1 \times \mathrm{CO}_{2}$ simulation. The energy cycle was characterized by a decrease in the available potential energies $\left(A_{Z}\right.$ and $\left.A_{E}\right)$, with a consequent reduction in the conversion between $A_{Z}$ to $A_{E}$ and $A_{E}$ to $K_{E}$. The values of zonal kinetic energy $\left(K_{Z}\right)$ and the conversion between $A_{E}$ and $K_{E}$ increased, while $K_{E}$ values decreased.

Hernández-Deckers and von Storch [31] based on equilibrium and transient simulations with a coupled atmosphereocean GCM showed that the intensity of the Lorenz energy cycle, given by the total conversion rate of potential into kinetic energies, is reduced in a atmosphere with doubled $\mathrm{CO}_{2}$ concentration, corroborating the results of [20]. This reduction is attributed to the decrease in the conversions from potential to kinetic energy of both zonal and eddy modes. Furthermore, they observed an increase (decrease) in the zonal (eddy) kinetic energy reservoir as a response to the increasing of the barotropic (baroclinic) conversion. They found a dual role of the warming pattern in the atmosphere: an increase of $A_{Z}$ in the upper troposphere followed by a weakening of $A_{Z}$ in low levels, with the increase in the static stability being the cause of the former. According to Hernández-Deckers and von Storch [32], based on two equilibrium runs $\left(1 \times \mathrm{CO}_{2}\right.$ and $\left.2 \times \mathrm{CO}_{2}\right)$ from the coupled atmosphere-ocean ECHAM5/MPI-OM model, the dual response (strengthening in the upper troposphere and weakening below) concerns mainly the transient eddy terms, with the stationary eddies playing a secondary importance.

As seen in the previous works, the atmospheric energetics are broadly modified by significant changes in their composition, as is the case of $\mathrm{CO}_{2}$ increasing. Although the direction of the fluxes evolved in the Lorenz energy cycle is not modified in case of warmed climate drove by the increasing of $\mathrm{CO}_{2}$, the fluxes present changes, which concerns important dynamical processes (e.g., barotropic and baroclinic activities). In this context, the new set of available data relative to the Representative Concentration Pathways is an excellent opportunity to explore the atmospheric energetics under the increasing of greenhouse gases, land use change, and pollution emissions.

The paper is organized as follows: Data and Methodology are discussed in Section 2, and the main results are presented in Section 3, with a discussion of time series of energy and conversion terms and volume-integrated energy components. A follow-up discussion is presented in Section 4, commenting on new insights and perspectives brought by the results.

\section{Data and Methodology}

In this study, we use a set of four experiments originating from the new Max Planck Institute Earth System Model
(MPI-ESM) used in the Coupled Model Intercomparison Project phase 5 (CMIP5). The MPI-ESM consists of the atmosphere model ECHAM6 [34], including a land vegetation module and the ocean model MPIOM [35]. The MPI-ESR-MR model has a spatial resolution equivalent to $1.875^{\circ} \times 1.875^{\circ}$ on a Gaussian grid, as the model runs with a horizontal resolution of 63 waves triangular spectral truncated and 95 levels in the vertical (T63L95), see [36]. The ocean component of the MPI-ESM, MPIOM, is a freesurface ocean general circulation model formulated on an Arakawa-C grid in the horizontal and a z-grid in the vertical. The MPIOM horizontal resolution translates into a grid ranging from $15 \mathrm{~km}$ around Greenland to $185 \mathrm{~km}$ near the equator, for more details see [37]. Within the set of runs designed from CMIP5, we have considered three RCPs [38, 39]: (1) one mitigation scenario leading to a very low radiative forcing level of $2.6 \mathrm{~W} / \mathrm{m}^{2} \mathrm{RCP} 26$ [40], (2) one medium stabilization scenario RCP45 [41], and (3) one representative of a very high emission scenario RCP85 [42]. A historical experiment, representing the control experiment (CTRL), is used here for comparison purposes. The historical experiment covers much of the industrial period from the mid-19th century to near present (18802005); however, we used here the period from 1979 to 1999 as the base period. The RCPs experiments continue from the historical run until 2100. The RCPs are characterized in terms of land use cover, greenhouse gas $\left(\mathrm{CO}_{2}, \mathrm{CH}_{4}\right.$, and $\mathrm{N}_{2} \mathrm{O}$ ), and air polluting scenario projections (e.g., $\mathrm{SO}_{2}$ and $\mathrm{NO}_{x}$ ) [43]. To analyze the impact of the different rate of greenhouse gas emissions on the global and hemispherical $L E C$, mean daily atmospheric data of zonal and meridional components of the horizontal wind vector ( $u$ and $v$ ), air temperature $(T)$, vertical component of velocity in pressure coordinates $(\omega=d p / d t)$, and geopotential height $(z)$ are used. The atmospheric variables were integrated from the lowest model level, considered to be at the surface $(1000 \mathrm{hPa})$ up to $1 \mathrm{hPa}$. The impacts are quantified in terms of anomaly produced in the comparison between the RCPs and the control experiments. The period of analysis covers two specific ranges: 1979-1999 and 2079-2099, hereafter called Late 20th century (L20C) and Late 21st century (L21C), respectively.

The simplest representation of the Lorenz energetics is the two-component energy cycle (Figure 1(a)), see [33].

Consider

$$
\begin{gathered}
\frac{\partial A}{\partial t}=-C(A, K)+G \\
\frac{\partial K}{\partial t}=C(A, K)-D
\end{gathered}
$$

where $A$ is the amount of available potential energy, $G$ its generation rate, $C$ is the energy conversion between $A$ and kinetic energy $K$, and $D$ is the dissipation rate of $K$. When $C(A, K)$ is positive, $K$ increases at the expense of $A$, and vice versa. 


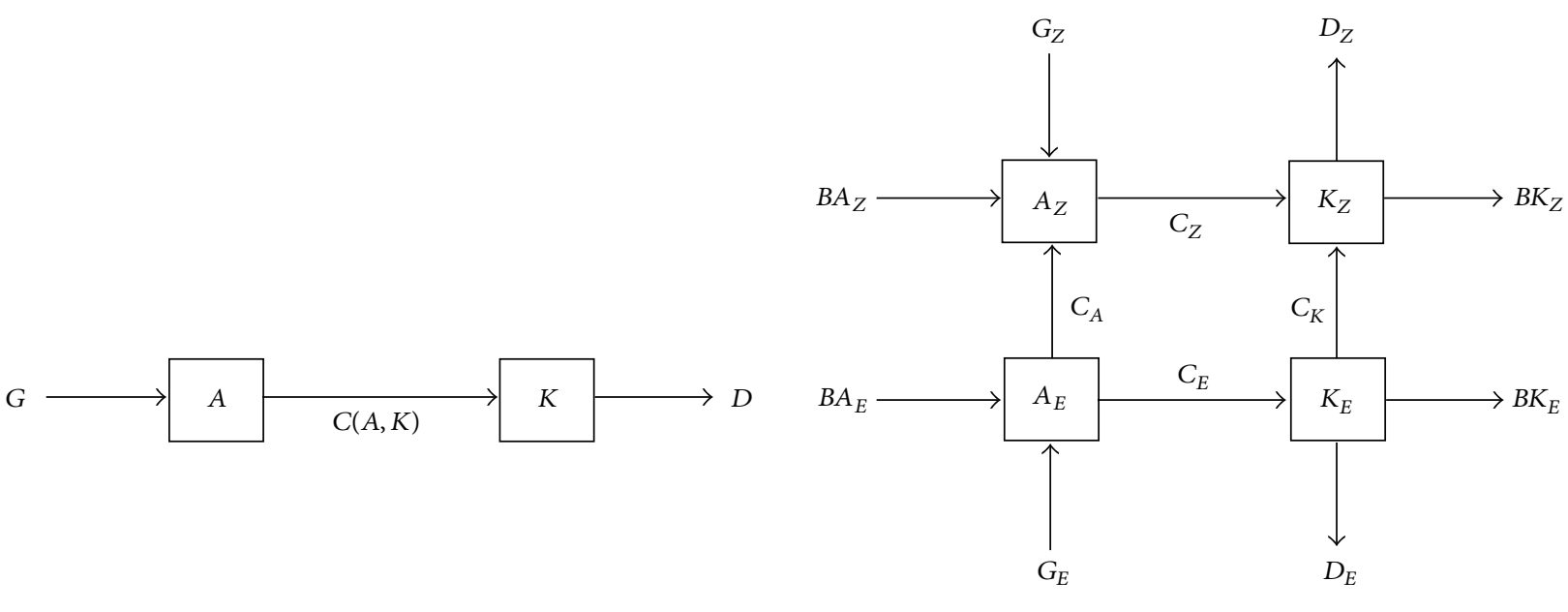

(a)

(b)

FIGURE 1: Lorenz energy cycle representation for (a) two-component energy cycle in which available potential energy denoted by the letter $A$ is generated $(G)$, converted $(C)$ to kinetic energy $(K)$, and subsequently dissipated $(D)$. (b) Four-component energy cycle with $A$ and $K$ decomposed into mean and eddy parts. Adapted from [33].

The four-component energy cycle is characterized by the subdivision of $A$ and $K$ into their zonal and eddy components and the set of equations can be written as

$$
\begin{gathered}
\frac{\partial A_{Z}}{\partial t}=-C_{Z}-C_{A}+G_{Z} \\
\frac{\partial A_{E}}{\partial t}=C_{A}-C_{E}+G_{E}, \\
\frac{\partial K_{Z}}{\partial t}=C_{K}+C_{Z}-D_{Z} \\
\frac{\partial K_{E}}{\partial t}=C_{E}-C_{K}-D_{E} .
\end{gathered}
$$

In the four-component energy cycle the potential energy is portioned into zonal available potential energy $\left(A_{Z}\right)$ and eddy available potential energy $\left(A_{E}\right)$. The kinetic energy can be treated similarly as potential energy; that is, the kinetic energy of the flow can be separated into its zonal $\left(K_{Z}\right)$ and eddy $\left(K_{E}\right)$ parts. In the energy cycle of Lorenz, $A_{Z}$ and $A_{E}$ are produced by generation processes named $G_{Z}$ and $G_{E}$, while reservoirs of energy are connected by conversion terms $C_{Z}$, $C_{A}, C_{E}$, and $C_{K}$ (resp, the conversion from $A_{Z}$ to $K_{Z}, A_{Z}$ to $A_{E}, A_{E}$ to $K_{E}$, and $K_{E}$ to $K_{Z}$ ). The $C_{Z}$ term involves transport of sensible heat by meridional circulation affecting $A_{Z}$ and $K_{Z}$ by altering the variance of zonally averaged temperature and wind. It depends upon the covariance between zonal means of vertical velocity and temperature, and it reflects the growth of $K_{Z}$ at the expense of $A_{Z}$ when there is warm air rising and cold air sinking in the same latitude. The $C_{A}$ involves horizontal and vertical eddy-transports of sensible heat. This term affects $A_{Z}$ and $A_{E}$ by altering the variance of temperature and depends upon the transport of sensible heat along the gradients of zonal averaged temperature. The $C_{E}$ term involves vertical eddy-transports of sensible heat, whose values by unit area are independent of latitude. It affects $A_{E}$ and $K_{E}$ by altering the variance of temperature and wind within latitude circles, and its absolute value indicates to what extent an environment is baroclinic. The term $C_{K}$ involves horizontal and vertical eddy-transports of momentum, and it depends upon the transport of angular momentum along the gradients of angular velocity. The absolute value of $C_{K}$ indicates to what extent an environment is barotropic or supports atmospheric disturbances to intensify via barotropic conversion.

For the case of open domains the four-components energy cycle (Figure 1(b)) must include the boundary and work done processes.

Consider

$$
\begin{gathered}
\frac{\partial A_{Z}}{\partial t}=-C_{Z}-C_{A}+B A_{Z}+G_{Z}, \\
\frac{\partial A_{E}}{\partial t}=C_{A}-C_{E}+B A_{E}+G_{E}, \\
\frac{\partial K_{Z}}{\partial t}=C_{K}+C_{Z}+B K_{Z}+B \Phi Z-D_{Z}, \\
\frac{\partial K_{E}}{\partial t}=C_{E}-C_{K}+B K_{E}+B \Phi E-D_{E} .
\end{gathered}
$$

$B A_{Z}, B A_{E}, B K_{Z}$, and $B K_{E}$ terms, respectively, represent fluxes of $A_{Z}, A_{E}, K_{Z}$, and $K_{E}$ from the lateral and vertical boundaries. $B \Phi Z$ and $B \Phi E$ terms denote the dynamical mechanisms in which they produce or destroy kinetic energy. As described by [44], this is due to the fact that $B \Phi Z, B \Phi E$, $C_{Z}$, and $C_{E}$ derivatives involve a single term in the form $V \cdot \nabla \Phi$ which represents the appearance of kinetic energy via a crossisobaric flow towards low pressure. The destruction of kinetic energy occurs when there is cross-isobaric flow towards the high pressure. However, here $B \Phi Z$ and $B \Phi E$ are added to the dissipation term. 
The last two terms in (3c) and (3d) can be determined in form of residuals, with the incorporation of calculation errors $\varepsilon K_{Z}$ and $\varepsilon K_{E}$ in the following form:

$$
\begin{gathered}
R K_{Z}=B \Phi Z-D_{Z}+\epsilon K_{Z} \\
R K_{E}=B \Phi E-D_{E}+\varepsilon K_{E}
\end{gathered}
$$

In similar form, the intrinsic errors resulting from the numerical estimations for the other terms in (3a) and (3b) are also included in the estimation of the generation terms:

$$
\begin{aligned}
& R G_{Z}=G_{Z}+\varepsilon A_{Z}, \\
& R G_{E}=G_{E}+\varepsilon A_{E} .
\end{aligned}
$$

Detailed mathematical expressions for all components of the energy budget, as described by (3a) and (3d) are presented in the appendix.

Here the Lorenz diagram considers that the conversion terms are always positive, with the arrows indicating the direction of the fluxes. The rates of generation of available potential energy and dissipation of kinetic energy are obtained as residuals by considering that in the long run the gain or loss of potential and kinetic energy is negligible. The four-component energy cycle is used in this study for both global and hemispherical energetics. However, in the first case the boundary fluxes are not included.

\section{Results}

3.1. Time Series of Energy and Conversion Terms. The climatological annual cycles of generation, available potential energy and kinetic energy, with their zonal and eddy components, for the control and RCPs experiments for the whole globe are illustrated in Figure 2. The error bars, indicating the 95\% confidence level about the mean, are included in this panel to show the interannual variation experienced by the energy terms. The values of $G_{Z}$ are maximized in May and September followed by two minimum during June and January (Figure 2(a)). The results show diminishing of $G_{Z}$ as greenhouse gases concentration increases. An opposite behavior is observed for $G_{E}$ (Figure 2(b)). In this case $G_{E}$ presents high negative values in the control experiment and declines to minimum negative values for RCP85 experiment. The implications of the fall of $G_{Z}$ and $G_{E}$ (negatively) as the concentration of greenhouse gases increases are that less $A_{Z}$ and $A_{E}$ are created by diabatic processes and consequently affecting the release of $K_{Z}$ and $K_{E}$ in the atmosphere by the conversion terms. The decrease in the generation of available potential energy occurs due to the fact that in a warmed planet the horizontal temperature gradient is reduced, as can be seen from Figure 1 of [20] and Figure 2 of [31].

According to Figure 2(c) the zonal available potential energy is characterized by a well-defined seasonal variation in the case of RCP26 and RCP45, while in the RCP85 experiment the seasonal variations is less visible. The impact of increasing in greenhouse gases is stronger in the RCP45 and RCP85 when compared with the control experiment. The bars of control and RCP26 experiments overlap each other in the major part of the year suggesting a weak impact in comparison with other RCPs. A similar pattern is observed for the eddy available potential energy (Figure 2(d)), in which RCP45 and RCP85 experiments produce the strongest impact. The reduction of the seasonal variations as the concentration of greenhouse gases increases is clear. The results still show that there is decrease of the available potential energies $\left(A_{Z}\right.$ and $\left.A_{E}\right)$ due to the drop of the generation terms. As can be seen, the strongest (weakest) weakening in the available potential energy, for both zonal and eddy parts, occurs preferentially in the high (low) range emission experiments. The decreasing in $A_{E}$ as the concentration of greenhouse gases increases is because less $A_{E}$ is destructed or converted into $G_{E}$. The destruction of $G_{E}$ occurs when colder air is advected to warmer regions and warmer air is advected to colder regions in the same latitude, a process that alters the variance (correlation) of diabatic heat and the temperature field. A brief discussion about the role of this term in produced available potential energy is found in Lorenz [2]; however, a more thorough discussion about this term is limited by the absence of diabatic heating/cooling data from the global circulation models. Figures 2(e) and 2(f) show the values of kinetic energies $\left(K_{Z}\right.$ and $\left.K_{E}\right)$ as function of the RCPs and CRTL experiments. The annual cycle of $K_{Z}$ is characterized by a well-defined seasonal variation, with highest (lowest) values from July to September (April to June). One can see that $K_{Z}$ clearly increases, while $K_{E}$ remains approximately unchanged around the year as the concentration of greenhouse gases increases. The increase of $K_{Z}$ occurs in the RCP85 forcing scenario, with minor and almost equally changes in RCP45 and RCP26. As the generation (or destruction) of $K_{Z}$ depends upon the joint effect of the transport of angular momentum along the gradients of angular velocity $\left(C_{K}\right)$, transport of sensible heat by meridional circulation $\left(C_{Z}\right)$ and the dissipation of kinetic energy by friction, represented by $D_{Z}(2 \mathrm{c})$, and an evaluation of the conversion terms are necessary.

The global climatological annual cycles of the verticallyintegrated conversion and dissipation terms for the control and RCPs experiments are presented in Figure 3. It can be seen that $C_{A}$ and $C_{K}$ conversions are significantly altered, between the months of June and August, in the RCPs scenarios forcing (Figures 3(b) and 3(d)), with the strongest changes occurring in the RCP85. The results show a decrease in the transfer of energy from $A_{Z}$ to $A_{E}$ as the concentration of greenhouse gases increases, probably because of the reduction of the eddy-transports of sensible heating. This is expected in a warmed environment with less horizontal contrast of temperature. Reference [31] showed that in a warmed planet with doubled $\mathrm{CO}_{2}$ concentration, the meridional temperature gradient decreases due to the anomalous heating in the tropical and polar regions. The changes in $C_{Z}$ and $C_{E}$ are modest and not statistically significant (Figures 3(a) and 3(c)), suggesting a weak relation to the increasing of greenhouse gases concentration. The term $C_{K}$, which acts around the year as a source of energy for the reservoir of $K_{Z}$, shows different result. It indicates 


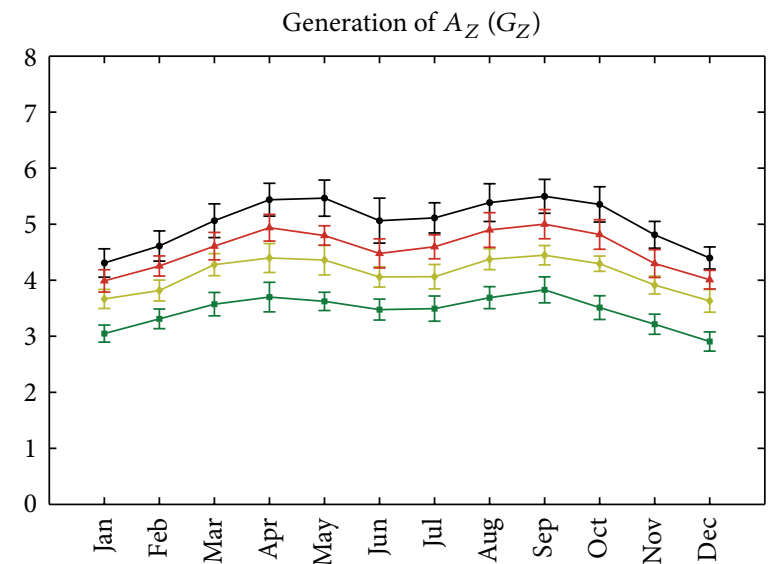

(a)

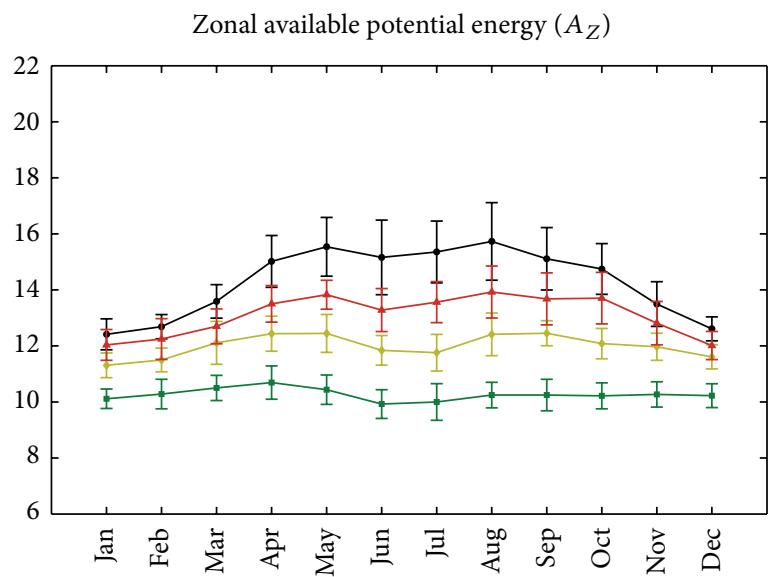

(c)

Zonal kinetic energy $\left(K_{Z}\right)$

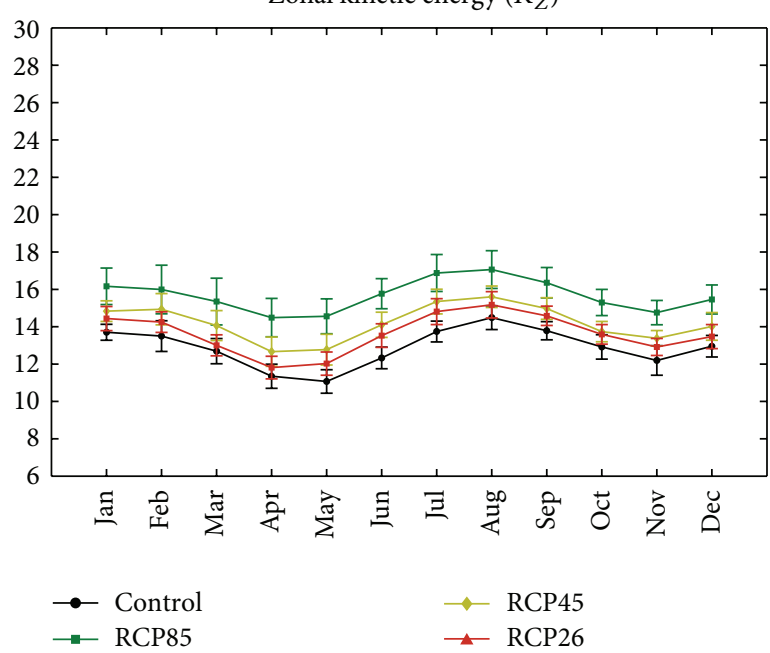

(e)

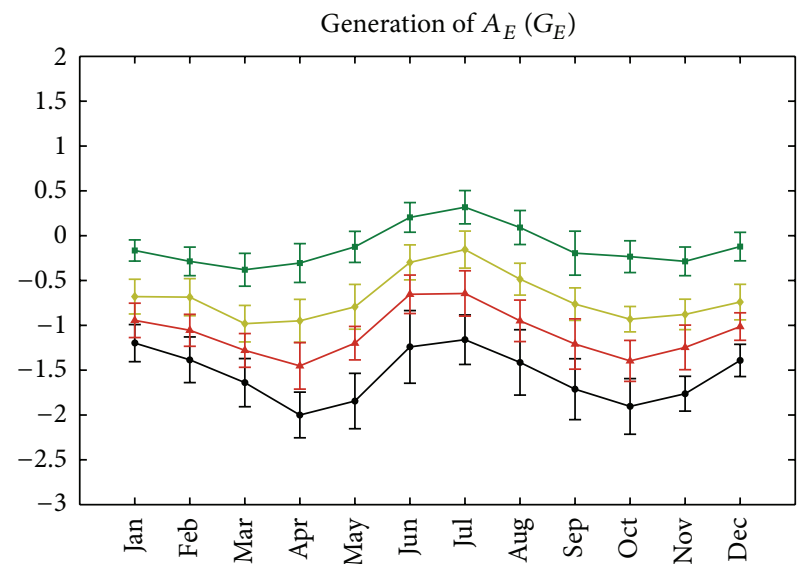

(b)

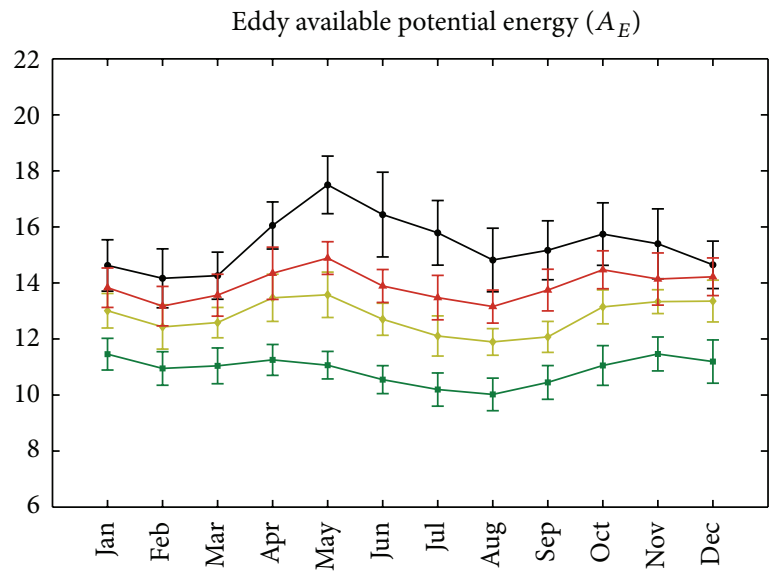

(d)

Eddy kinetic energy $\left(K_{E}\right)$

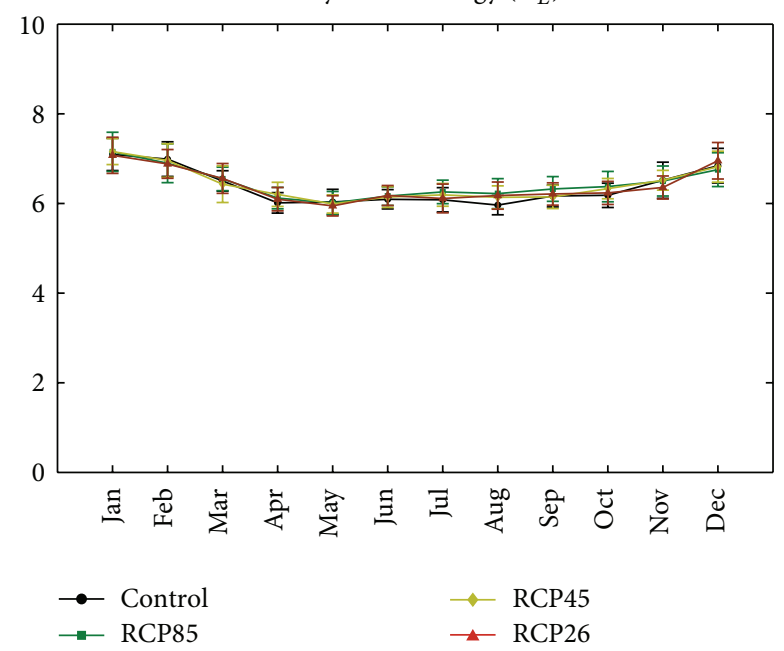

(f)

Figure 2: Climatology of the generation terms $G_{Z}(\mathrm{a})$ and $G_{E}(\mathrm{~b})$, and the energy terms $A_{Z}$ (c), $A_{E}(\mathrm{~d}), K_{Z}(\mathrm{e})$, and $K_{E}$ (f) for a global domain integrated between 1000 and $1 \mathrm{hPa}$ for RCP85, RCP45, RCP26, and control experiments. Error bars indicate 95\% confidence intervals about the mean. Units are $10^{5} \mathrm{~J} / \mathrm{m}^{2}$ for reservoirs and $\mathrm{W} / \mathrm{m}^{2}$ for generation terms. 


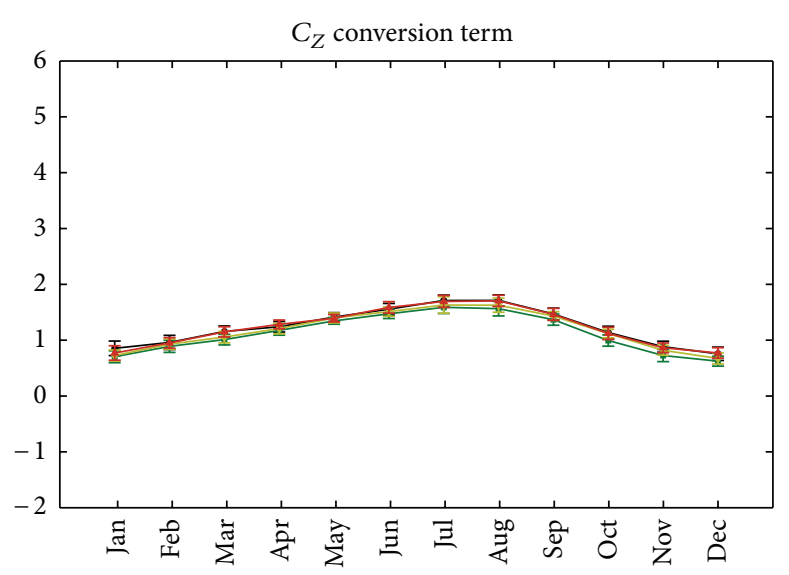

(a)

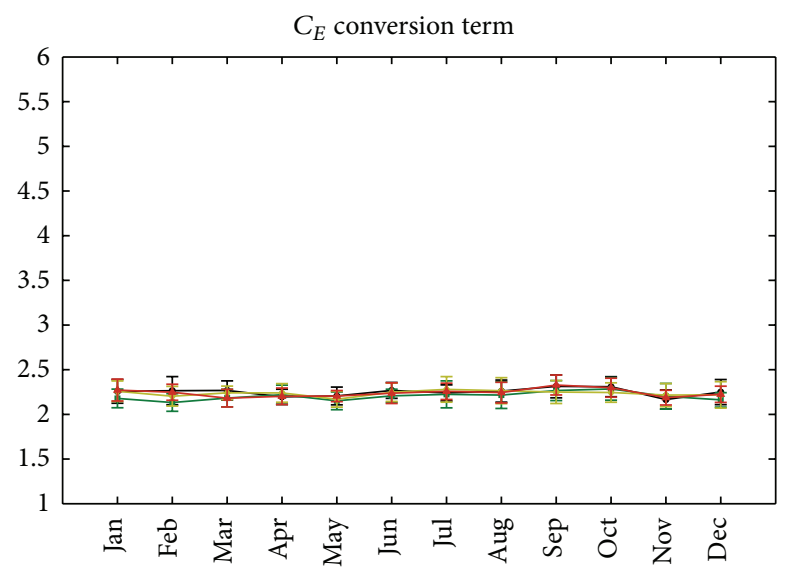

(c)

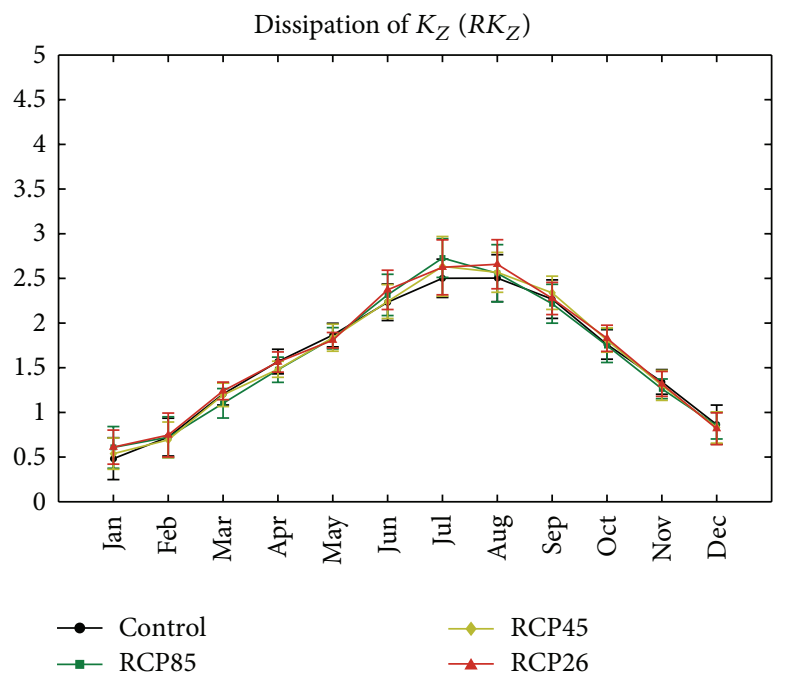

(e)

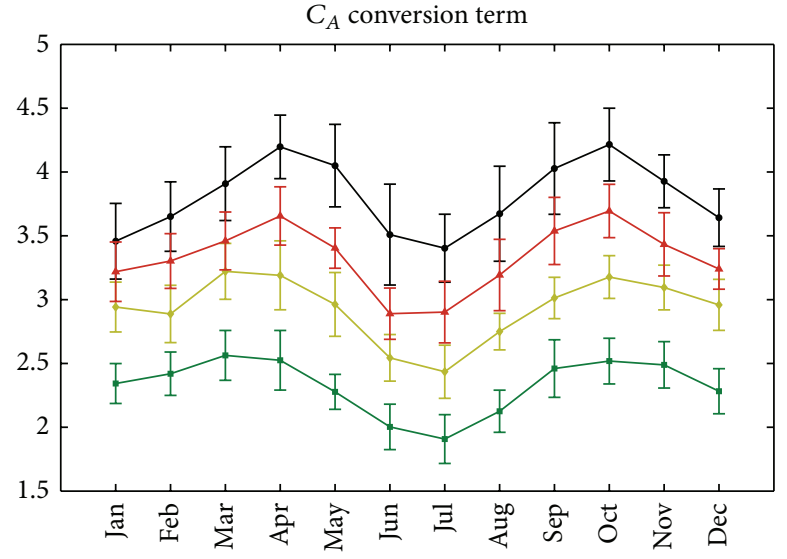

(b)

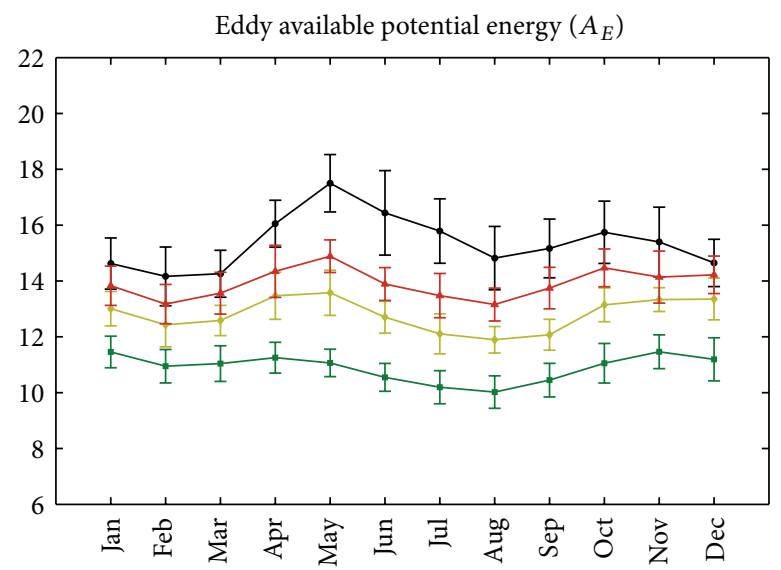

(d)

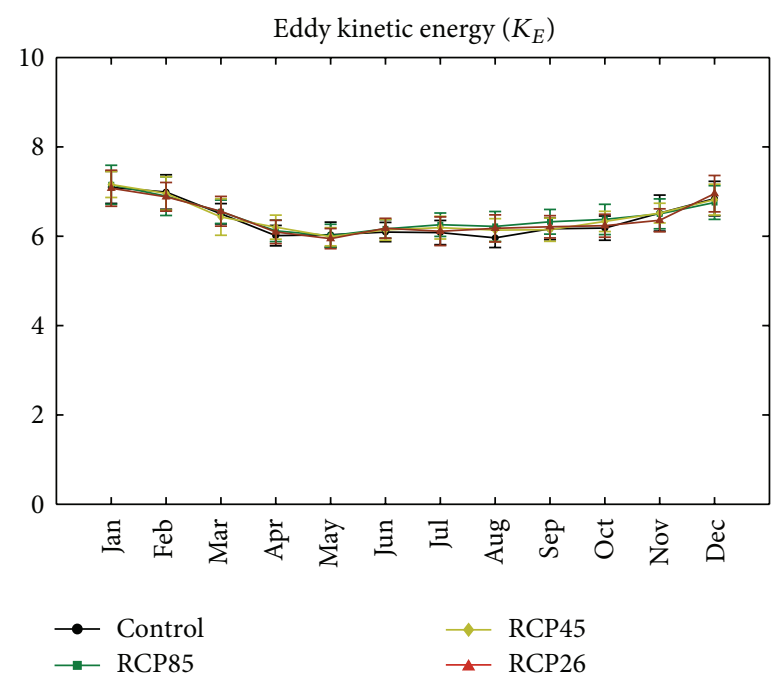

(f)

Figure 3: Climatology of the conversion terms $C_{Z}$ (a), $C_{A}$ (b), $C_{E}(\mathrm{c})$, and $C_{K}$ (d) for the whole globe integrated between 1000 and $1 \mathrm{hPa}$ for RCP85, RCP45, RCP26, and control experiments. Error bars indicate 95\% confidence intervals about the mean. Units are W/m². 


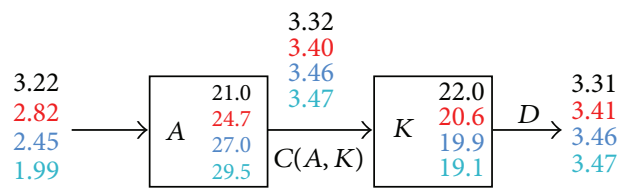

(a)

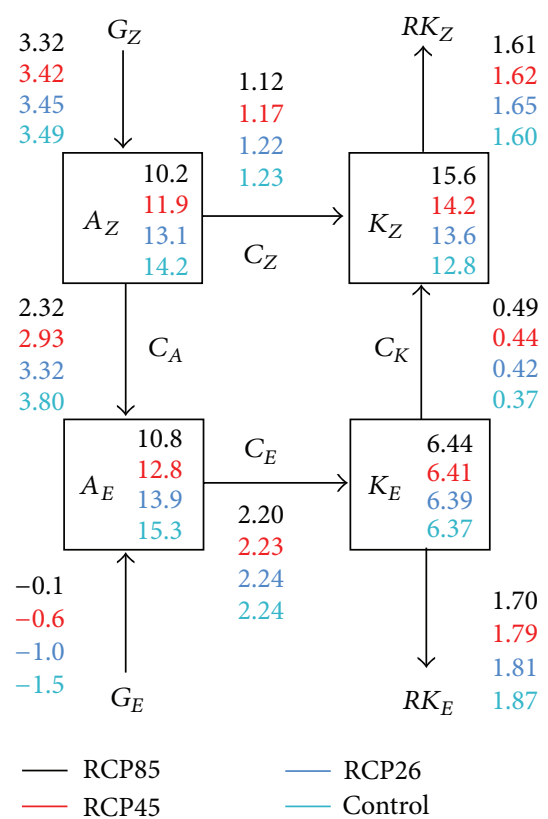

(b)

FIGURE 4: Representation of annual mean of spatial domain Lorenz energy cycle for the entire globe in which (a) is representative of a twocomponent energy cycle and (b) denotes the four-components diagram. Values from up to below in each figure are for RCP85, RCP45, RCP26, and control experiments. Units are $10^{5} \mathrm{~J} / \mathrm{m}^{2}$ for reservoirs and $\mathrm{W} / \mathrm{m}^{2}$ for conversion, generation, and dissipation terms. In the two-component energy cycle the value of $G$ is given by the sum of its zonal and eddy part $\left(G=G_{E}+G_{Z}\right), A=A_{Z}+A_{E}, C(A, K)=C_{Z}+C_{E}, K=K_{Z}+K_{E}$, and $D=R K_{Z}+R K_{E}$. Arrows indicate the direction corresponding to positive values; negative values imply opposite flux direction.

that in a warmed climate the conversion from $K_{E}$ to $K_{Z}$ increases; that is, there is an increase of eddy-transports of angular momentum along the gradients of angular velocity. Figures 3(e) and 3(f) show an opposite behavior between the dissipation of $K_{Z}$ and $K_{E}$ during the course of the year; that is, $R K_{Z}$ presents the highest values from July to September, when $R K_{E}$ is minimum. The same relation is observed from November to January. These results show that the zonal mean motions are strongly dissipated by friction processes when they are maximized (Figure 2(e)). The same behavior is observed for the eddy motions.

3.2. Volume-Integrated Energy Components. The mean annual energy cycle (two- and four-component) for the entire globe, southern and northern hemispheres calculated from RCPs and historical experiments are presented, respectively, in Figures 4, 5, and 6. The two-component energy cycle for the global domain (Figure 4(a)) shows an increase in the generation term $G$ as a response to the increasing in greenhouse gases concentration, followed by a decrease in the available potential energy $A$, conversion term $C(A, K)$ and the dissipation $D$. However, the total kinetic energy increases. Each of these terms is characterized by the sum of its four-component energy cycle (Figure 4(b)). As can be noted, the increase in $G$ is $~ 61 \%(44 \%, 23 \%)$ in the case of RCP85 (RCP45 and RCP26). The others components have the following conditions: decreasing in $A$ of $~ 28 \%(16 \%$, $8 \%)$, decreasing in $C(A, K)$ of $\sim 4 \%(2 \%, 0.2 \%)$, increasing in
$K$ of $\sim 15 \%(7 \%, 4 \%)$, and a decreasing in the dissipation term $D$ of $\sim 4 \%(1 \%, 0.2 \%)$.

The four-component energy cycle (Figure 4(b)) indicates a general decrease in the values of generation, available potential energy, the conversion terms $C_{Z}, C_{A}$, and $C_{E}$, and the dissipation terms as the concentration of greenhouse gases increases. The results show that RCP85 are the experiment with the maximum reduction relative to control experiment. Kinetic energy and the conversion term $C_{K}$ are quantities that increase as the greenhouse gases concentration rises, as can be confirmed from RCPs forcing scenarios. It can be seen that both available potential energies present similar reduction, $\sim 28 \%$ for RCP 85 and below $10 \%$ in the case of RCP26 experiment. The reservoirs of kinetic energy are increased, in which the zonal part presenting the strongest change, that is, an increasing of $21.8 \%$ in $K_{Z}$ versus a small increase of $\sim 1 \%$ in $K_{E}$ for the RCP85 experiments. This is suggestive of a strengthening of the atmospheric zonal motions. The strength of the baroclinic energy flow, characterized by the conversion from $A_{Z}$ to $A_{E}\left(C_{A}\right)$ and $A_{E}$ to $K_{E}\left(C_{E}\right)$, is reduced in a condition of warmed climate, as can be seen by the reduction of $\sim 39 \%$ in $C_{A}$ and $\sim 1.8 \%$ in $C_{E}$ for the RCP85 experiments. In the case of RCP 45 and RCP26, the reduction is less strong. The barotropic flow, denoted by the transfer of energy between $K_{E}$ and $K_{Z}\left(C_{K}\right)$, is increased showing that the zonal flow grows at the expense of the eddy motion. The conversion term $C_{Z}$, responsible by the increasing of kinetic energy due to the meridional exchange of mass in the vertical plane, is reduced. These results are attributed to the 


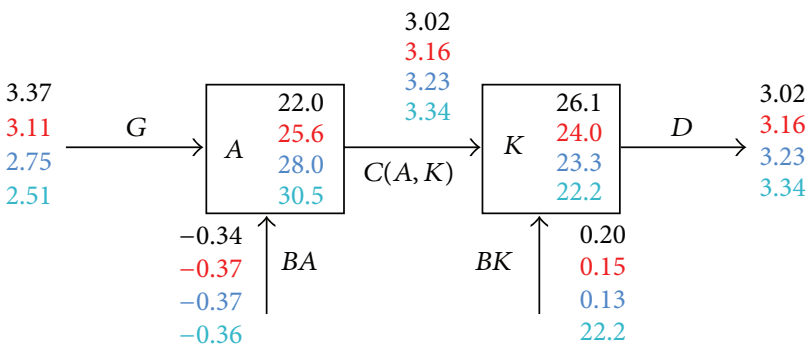

(a)

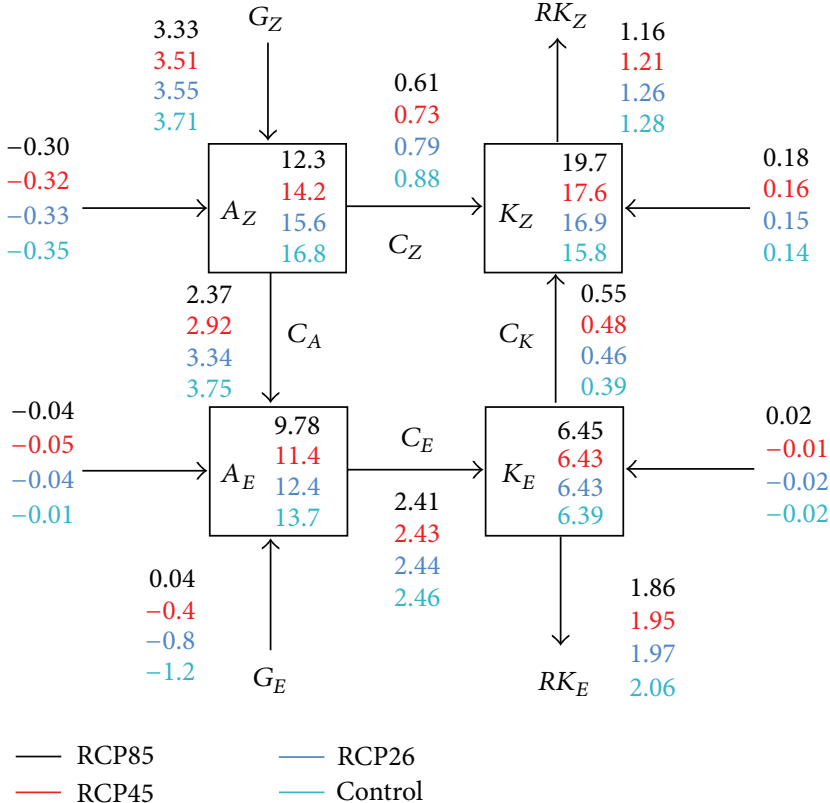

(b)

FIGURE 5: Representation of annual mean of spatial domain Lorenz energy cycle for the Southern Hemisphere in which (a) is representative of a two-component energy cycle and (b) denotes the four-component diagram. The boundaries of available potential energy $\left(B_{A}\right)$ and kinetic energy $\left(B_{K}\right)$ are included in the two-component energy cycle. Values from up to below in each figure are for RCP85, RCP45, RCP26, and control experiments. Units are $10^{5} \mathrm{~J} / \mathrm{m}^{2}$ for reservoirs and $\mathrm{W} / \mathrm{m}^{2}$ for conversion, generation, and dissipation terms. Arrows indicate the direction corresponding to positive values; negative values imply opposite flux direction.

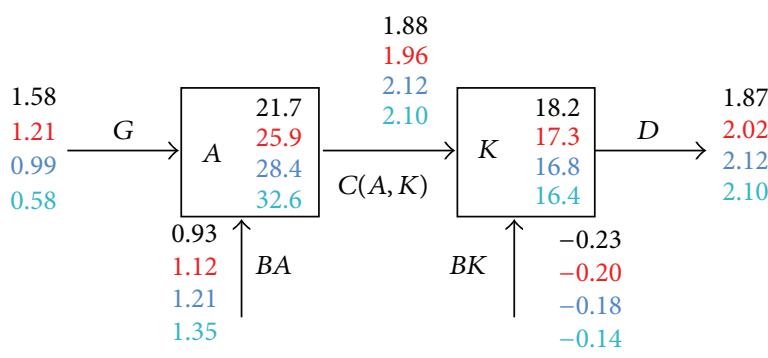

(a)

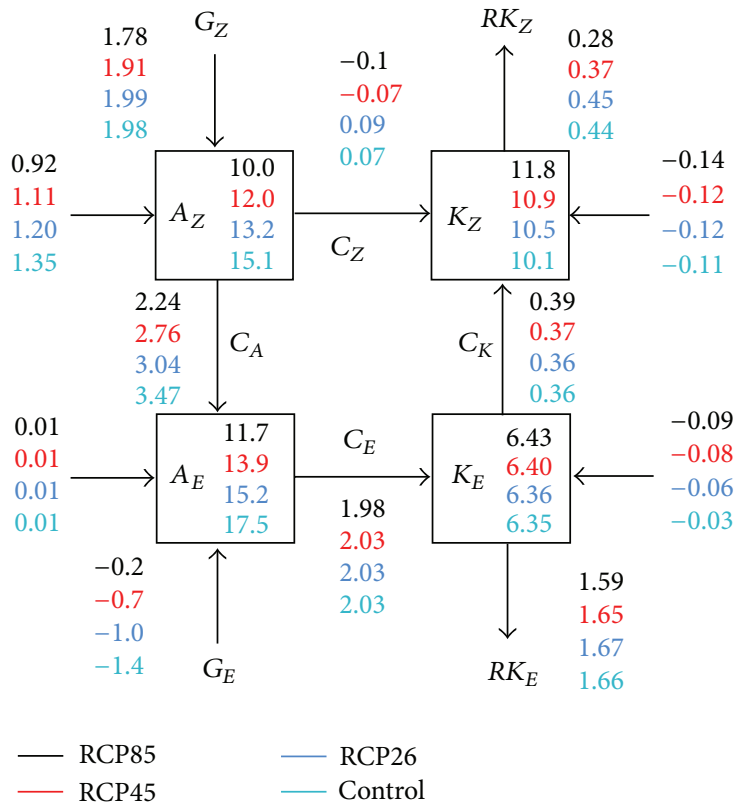

(b)

FIGURE 6: Representation of annual mean of spatial domain Lorenz energy cycle for the Northern Hemisphere in which (a) is representative of a two-component energy cycle and (b) denotes the four-component diagram. The boundaries of available potential energy $\left(B_{A}\right)$ and kinetic energy $\left(B_{K}\right)$ are included in the two-component energy cycle. Values from up to below in each figure are for RCP85, RCP45, RCP26, and control experiments. Units are $10^{5} \mathrm{~J} / \mathrm{m}^{2}$ for reservoirs and $\mathrm{W} / \mathrm{m}^{2}$ for conversion, generation, and dissipation terms. Arrows indicate the direction corresponding to positive values; negative values imply opposite flux direction. 
less available potential energy that is produced in a warmed planet.

The two-component energy cycle for the $\mathrm{SH}$ domain displayed in Figure 5(a) shows an increase in the generation term $G$, followed by a decrease in the available potential energy $A$, conversion term $C(A, K)$, and the dissipation $D$. The figure still shows a negative decrease in the flux of $A\left(B_{A}\right)$ and an increase in the flux of $K\left(B_{K}\right)$. Thus, $B_{A}$ acts as sink of $A$, and it is less intense for a warmed climate, while $B K$ acts as a source of $K_{Z}$. As can be observed, the increase in $G$, in the case of $S H$ domain, is $~ 34 \%(24 \%, 9 \%)$ in the case of RCP 85 (RCP45 and RCP26). The total available potential energy decreases by $\sim 27 \%(16 \%, 8 \%)$, followed by a negative decrease of $\sim 5 \%(3 \%, 3 \%)$ in the $B_{A}$. The decrease in $C(A, K)$ is $\sim 9 \%(5 \%, 3 \%)$, with an increasing in $K$ of $\sim 17 \%(8 \%, 5 \%)$, an increase of $\sim 66 \%(25 \%, 8 \%)$ in the $B_{K}$ and a decrease in the dissipation term $D$ of $~ 9 \%$ (5\%, 3\%).

The four-component energy cycle displayed in Figure 5(b) indicates a general decrease in the values of generation, available potential energy, the conversion terms $C_{Z}, C_{A}$, and $C_{E}$, and the dissipation terms as the concentration of greenhouse gases increases. Kinetic energy and the conversion term $C_{K}$ are quantities that increase as the greenhouse gases concentration rises, as can be confirmed from RCPs forcing scenarios. In the four-component energy cycle it can be seen that the negative reduction in the boundary terms associated to the available energies is due mainly to the $B A_{Z}$, as the reduction in $B A_{E}$ is one order magnitude small. The increase in the kinetic energy boundary terms is particularly due to the $B K_{Z}$ term. The energy reservoirs of available energies and kinetic energies, respectively, decrease and increase. For the RCP85 experiment the increase of $K_{E}$ is small ( 1\%) when compared with increases in $K_{Z}(\sim 24 \%)$. Both decrease and increase values in the energy reservoirs are more significant in the case of highest greenhouse gases emissions. The baroclinic flow, characterized by positive values of $C_{A}$ and $C_{E}$, decreases as the planet warms, followed by an increase in the barotropic component, and a reduction in the $C_{Z}$ values. These patterns are similar to the global domain.

Figure 6(a) shows the two-component energy cycle for the $N H$ domain. The results show an increase in the generation term $G$, a decrease in the available potential energy $A$, a decrease in $B_{A}$, a decrease in the conversion term $C(A, K)$, an increase in $K$, a negative increase in $B_{K}$, and a decrease in the dissipation term $D$. In the $N H$ case, $B_{A}$ acts as source of $A$, and it is less intense for a warmed climate, while $B_{K}$ acts as a sinking of $K_{Z}$, and it is more intense for a warmed climate. As can be seen, the increase in $G$, in the case of $N H$ domain, is $172 \%(108 \%, 70 \%)$ in the case of RCP85 (RCP45 and RCP26). The total available potential energy has a decreasing of $~ 33 \%$ $(20 \%, 13 \%)$, followed by a decrease of $\sim 31 \%(17 \%, 10 \%)$ in the $B_{A}$. The decrease in the values of $C(A, K)$ is $\sim 10 \%(6 \%$, $1 \%)$, with an increasing in $K$ of $\sim 11 \%(6 \%, 2 \%)$, a negative increase of $\sim 64 \%(42 \%, 28 \%)$ in the $B_{K}$, and a decrease in the dissipation term $D$ of $\sim 10 \%$ ( $3 \%$, increase of $1 \%$ ).

In the four-component energy cycle for the $\mathrm{NH}$ (Figure 6(b)), observed is a pattern similar to the global and $S H$ domain, that is, reduction in the values of available potential energies, followed by a respective small and a significant increase in $K_{E}$ and $K_{Z}$, reduction in the generation terms, reduction in the baroclinic flux, increase in $C_{K}$, and reduction in the dissipation terms. The results also show a reduction in the boundary terms associated to the available energies is mainly due to the $B A_{Z}$, as the reduction in $B A_{E}$ is inexistent. The negative increase in the kinetic energy boundary terms is particularly strong in both terms.

As can be seen, the reductions and increases in the energetics still depend on the domain evaluated. For example, in the case of RCP85 projection the increase of $K_{Z}$ for the global domain is $\sim 21.8 \%$ relative to the control experiment, while $K_{Z}$ in the $S H$ and $\mathrm{NH}$ increases about $24.6 \%$ and $18.0 \%$, respectively. The same pattern of increase in $K_{Z}$ (and the remaining reservoirs) is followed by the others RCPs projection, though with less intensity.

For all analyzed domains the intensity of the $L E C$, measured by the conversion between potential and kinetic energy in both zonal and eddy modes, is reduced in a planet with more greenhouse gases, as noted from the values produced by the RCPs experiments. The largest reductions occur for the $\mathrm{NH}$ (10.35\%), when compared with global $(4.68 \%)$ and $S H(9.57 \%)$ domains. The strongest increase is seen to occur in the total kinetic energy for the $S H(\sim 17 \%)$, followed by an increase of $41.02 \%$ in $C_{K}$. This result indicates that the increase in $K_{Z}$ is related to the increase in $C_{K}$, as $K_{E}$ acts as a source of $K_{Z}$. However, another form to attribute the increase of $K_{Z}$ due to $C_{K}$ is to quantifying what dynamic process was the most important to the increase of $K_{Z}$. This can be achieved by evaluating or quantifying the terms involved in the calculation of $C_{K}$, see equation in the appendix. The first three terms of $C_{K}$ are related to the horizontal transport of momentum, while the last two terms deal with the vertical transport of momentum. The quantification of their changes for the RCPs experiments can bring us important characteristics about the atmospheric behavior in a climate change perspective.

For the $S H$ ( $N H$, Global) domain, the increase in $C_{K}$, in the RCP85, is related to an increase of $47.8 \%$ (5.2\%, $38.3 \%)$ in the horizontal eddy-transport of momentum and an increase of $23.9 \%(24.6 \%, 21.0 \%)$ in the vertical eddytransport of momentum relative to control experiment. For the experiments RCP26 and RCP45 the increase in the horizontal (vertical) eddy-transport of the $\mathrm{SH}$ is $22.8 \%$ (8.4\%) and $29.7 \%(10.1 \%)$, respectively, showing that in the $S H$ the increase in greenhouse gases produces an increase in both horizontal and eddy transport of momentum, with the former being more strong. In the case of the global domain, for RCP26 and RCP45, the increase of horizontal (vertical) eddytransport of momentum is $18.7 \%$ (6.1\%) and $25.0 \%$ (9.6\%), respectively, and for the $\mathrm{NH}$ domain, it corresponds to $-1.5 \%$ $(2.1 \%)$ and $2.2 \%(9.5 \%)$, respectively.

Calculations of changes for individual terms of $C_{A}$ indicate that the reduction in this component of the baroclinic conversion is due both horizontal and vertical eddy-transport of sensible heat. For the RCP85 experiment (RCP45 and RCP26) in the global domain, the reduction in the horizontal eddy-transport of sensible heat is $38.7 \%$ (22.9\% and $12.4 \%)$, while for the vertical eddy-transport of sensible heat, the 
change is of $77.7 \%$ (55.5\% and $33.3 \%$ ). For the $S H$ and $N H$ the reduction in the horizontal eddy-transport of sensible heat is of $35.1 \%(20.7 \%$ and $36.4 \%)$ and $39.2 \%(24,0 \%$ and $14.9 \%$ ), respectively, for the RCP85 (RCP45 and RCP26). The reduction in the vertical eddy-transport of sensible heat for the $\mathrm{SH}$ and $\mathrm{NH}$ is $22.2 \%$ (33.3\% and $55.5 \%)$ and $70 \%(52 \%$ and $38 \%$ ), respectively, for the RCP85 (RCP45 and RCP26). The reduction in the values of $C_{E}$ term is below $3 \%$ relatively to the control experiment for all RCPs.

\section{Concluding Remarks}

In this work a global and hemispherical energetic study, using the traditional Lorenz two- and four-component energy cycle, is carried out to access the impact of the radiative forcing relative to the greenhouse gases emission on the global and hemispherical LEC. The energetic analysis is based on the RCP85, RCP45, and RCP26 forcing experiments and a control simulation from the MPI-ESM-MR oceanatmosphere coupled model. The results show a decrease in most of the energy terms from the Lorenz energetics for the global domain, with few exceptions, suggesting a weakness of the LEC in the L21C period, as previous works have shown. However, here we have presented the changes in the Lorenz energetics related to the new RCPs scenarios, which are the results of the increase in greenhouse gases. In the previous literature, the energetics are quantified and evaluated under a condition of $\mathrm{CO}_{2}$ increasing only. In this context, we have evaluated and found that the increase in the barotropic component of the energy cycle, which is the main term responsible to the increase in the zonal component of the kinetic energy, is related to the increase in the horizontal transport of momentum, with a less increase in the vertical component. The reduction of the values in the energy cycle is evident and dependent of the RCP experiment, with the strongest reduction occurring in the highest radiative forcing experiment, RCP85. The results also show an increase in $C_{K}$, $K_{Z}$, and $K_{E}$ components of the LEC. Similar reduction in the intensity of the $L E C$ is observed for the $S H$ and $N H$, with RCP85 emission scenario influencing the most intense decrease in the energy terms. In Particular, for this scenario the energetic projection for the $\mathrm{SH}$ indicates an increase in $K_{Z}$ of $24.6 \%$, which is higher than the global $(21.8 \%)$ and $N H(18.0 \%)$ domains. The anomalous increase of $K_{Z}$ in the $\mathrm{SH}$ ( $\mathrm{NH}$ and Globe) for the $\mathrm{L} 21 \mathrm{C}$ period is attributed to an increase of $47.8 \%(5.2 \%, 38.3 \%)$ and $23.9 \%(21.0 \%, 24.6 \%)$, respectively, in the horizontal and vertical eddy-transport of momentum in RCP85. The increase in these transports are less intense for RCP45 and RCP26 mitigated scenarios. The reduction in the horizontal eddy-transport of sensible heat generates a decrease in the conversion between $A_{Z}$ and $A_{E}$, in the RCPs scenarios. These results contribute to the findings of $[20,31]$ who have shown that $C_{K}$ increases in a warmed climate; however, our results indicates that the increase in $C_{K}$ is mainly due the increase in the horizontal components of the momentum transport. The way and reason the increase of greenhouse gases emissions impact the transport of momentum and heat will be addressed in another work.
Although the results presented here are only based on one CMIP5 model and they do not probably represent a unique picture of the future behavior of energy cycle, they suggest important changes in the energetics of the atmosphere under a warmed climate, which can motivate further investigation on the atmosphere global circulation.

\section{Appendix}

\section{Lorenz Energetics}

Equations of Lorenz in spatial domain.

Mathematical expression of components in the energy balance (3a)-(3d).

The zonal mean of a variable $X$ between longitudes $\lambda_{1}$ and $\lambda_{2}$ is given by

$$
[X]_{\lambda}=\frac{1}{\lambda_{2}-\lambda_{1}} \int_{p_{1}}^{p_{2}} X d \lambda
$$

The eddy component of this variable is

$$
(X)_{\lambda}=X-[X]_{\lambda}
$$

The mean of $X$ over an area bounded by longitudes $\lambda_{1}$ and $\lambda_{2}$ and latitudes $\phi_{1}$ and $\phi_{2}$ is

$$
[X]_{\lambda \phi}=\frac{1}{\lambda_{2}-\lambda_{1}} \frac{1}{\sin \phi_{2}-\sin \phi_{1}} \int_{\phi_{1}}^{\phi_{2}} \int_{\lambda_{1}}^{\lambda_{2}} X \cos \phi d \lambda d \phi
$$

Define the quantity as

$$
\left([X]_{\lambda}\right)_{\phi}=[X]_{\lambda}-[X]_{\lambda \phi}
$$

The four energy forms in the SDLEC are

$$
\begin{gathered}
A_{Z}=\int_{p_{1}}^{p_{2}} \frac{\left[\left([T]_{\lambda}\right)_{\phi}^{2}\right]_{\lambda \phi}}{2[\sigma]_{\lambda \phi}} d p, \\
A_{E}=\int_{p_{1}}^{p_{2}} \frac{\left[(T)_{\lambda}^{2}\right]_{\lambda \phi}}{2[\sigma]_{\lambda \phi}} d p, \\
K_{Z}=\int_{p_{1}}^{p_{2}} \frac{\left[[u]_{\lambda}^{2}+[v]_{\lambda}^{2}\right]_{\lambda \phi}}{2 g} d p, \\
K_{E}=\int_{p_{1}}^{p_{2}} \frac{\left[(u)_{\lambda}^{2}+(v)_{\lambda}^{2}\right]_{\lambda \phi}}{2 g} d p,
\end{gathered}
$$

where $p_{1}$ and $p_{2}$ are, respectively, the upper and lower pressure boundaries, $T$ is the temperature, $g$ the magnitude of the acceleration of gravity, $u$ and $v$ are the eastward and 
northward components of the wind, respectively, and $\sigma$ is the static stability parameter which is given by

$$
\begin{aligned}
& {[\sigma]_{\lambda \phi}=\left[\frac{g T}{c_{p}}-\frac{g p}{R} \frac{\partial T}{\partial p}\right]_{\lambda \phi},} \\
& C_{Z}=\int_{p_{1}}^{p_{2}}-\left[\left([\omega]_{\lambda}\right)_{\phi}\left([T]_{\lambda}\right)_{\phi}\right]_{\lambda \phi} \frac{R}{g p} d p, \\
& C_{E}=\int_{p_{1}}^{p_{2}}-\left[(\omega)_{\lambda}(T)_{\lambda}\right]_{\lambda \phi} \frac{R}{g p} d p, \\
& C_{A}=\int_{p_{1}}^{p_{2}}-\left(\left[\frac{(v)_{\lambda}(T)_{\lambda}}{2[\sigma]_{\lambda \phi} r} \frac{\partial\left([T]_{\lambda}\right)}{\partial \phi}\right]_{\lambda \phi}\right. \\
& +\left[\frac{(\omega)_{\lambda}(T)_{\lambda}}{p^{R / c_{p}}}\right. \\
& \left.\left.\times \frac{\partial}{\partial p}\left(\frac{\left([T]_{\lambda}\right)_{\phi} p^{R / c_{p}}}{[\sigma]_{\lambda \phi}}\right)\right]_{\lambda \phi}\right) d p, \\
& C_{K}=\int_{p_{1}}^{p_{2}} \frac{1}{g}\left[(v)_{\lambda}(u)_{\lambda} \frac{\cos \phi}{r} \frac{\partial}{\partial \phi}\left(\frac{[u]_{\lambda}}{\cos \phi}\right)\right]_{\lambda \phi} d p \\
& +\int_{p_{1}}^{p_{2}} \frac{1}{g}\left[\frac{(v)_{\lambda}^{2}}{r} \frac{\partial[v]_{\lambda}}{\partial \phi}\right]_{\lambda \phi} d p \\
& +\int_{p_{1}}^{p_{2}} \frac{1}{g}\left[[v]_{\lambda}(u)_{\lambda}^{2} \frac{\tan \phi}{r}\right]_{\lambda \phi} d p \\
& -\int_{p_{1}}^{p_{2}} \frac{1}{g}\left[(\omega)_{\lambda}(u)_{\lambda} \frac{\partial[u]_{\lambda}}{\partial p}\right]_{\lambda \phi} d p \\
& +\int_{p_{1}}^{p_{2}} \frac{1}{g}\left[(\omega)_{\lambda}(v)_{\lambda} \frac{\partial[v]_{\lambda}}{\partial p}\right]_{\lambda \phi} d p
\end{aligned}
$$

where $r$ denotes the mean radius of the Earth.

The generation of APE terms and kinetic energy dissipation terms are

$$
\begin{gathered}
G_{Z}=\int_{p_{1}}^{p_{2}} \frac{\left[\left([q]_{\lambda}\right)_{\phi}\left([T]_{\lambda}\right)_{\phi}\right]_{\lambda \phi}}{c_{p}[\sigma]_{\lambda \phi}} d p, \\
G_{E}=\int_{p_{1}}^{p_{2}} \frac{\left[(q)_{\lambda}[T]_{\lambda}\right]_{\lambda \phi}}{c_{p}[\sigma]_{\lambda \phi}} d p,
\end{gathered}
$$

where $q$ denotes the diabatic processes associated with the generation of $A P E$.
The energy transport integrals are

$$
\begin{aligned}
& B A_{Z}=c_{1} \int_{p_{1}}^{p_{2}} \int_{\lambda_{1}}^{\lambda_{2}} \frac{1}{2[\sigma]_{\lambda \phi}} \\
& \times\left(2\left([T]_{\lambda}\right)_{\phi}(T)_{\lambda} u+\left([T]_{\lambda}\right)_{\phi}^{2} u\right)_{\lambda_{1}}^{\lambda_{2}} d \phi d p \\
& +c_{2} \int_{p_{1}}^{p_{2}} \frac{1}{2[\sigma]_{\lambda \phi}} \\
& \times\left(2\left[(v)_{\lambda}(T)_{\lambda}\right]_{\lambda}\left([T]_{\lambda}\right)_{\phi} \cos \phi\right. \\
& \left.+\left([T]_{\lambda}\right)_{\phi}^{2}[v]_{\lambda} \cos \phi\right)_{\phi_{1}}^{\phi_{2}} d p \\
& -\frac{1}{2[\sigma]_{\lambda \phi}}\left(\left[2(\omega)_{\lambda}(T)_{\lambda}\right]_{\lambda}\left([T]_{\lambda}\right)_{\phi}\right. \\
& \left.+\left[[\omega]_{\lambda}\left([T]_{\lambda}\right)_{\phi}^{2}\right]_{\lambda \phi}\right)_{p_{1}}^{p_{2}}, \\
& B A_{E}=c_{1} \int_{p_{1}}^{p_{2}} \int_{\phi_{1}}^{\phi_{2}} \frac{1}{2[\sigma]_{\lambda \phi}}\left[u(T)_{\lambda}^{2}\right]_{\lambda_{1}}^{\lambda_{2}} d \phi d p \\
& +c_{2} \int_{p_{1}}^{p_{2}} \frac{1}{2[\sigma]_{\lambda \phi}}\left(\left[(T)_{\lambda}^{2}\right]_{\lambda} \cos \phi\right)_{\phi_{1}}^{\phi_{2}} d p \\
& -\left(\frac{\left[\omega(T)_{\lambda}^{2}\right]_{\lambda \phi}}{2[\sigma]_{\lambda \sigma}}\right)_{p_{1}}^{p_{2}}, \\
& B K_{Z}=c_{1} \int_{p_{1}}^{p_{2}} \int_{\phi_{1}}^{\phi_{2}} \frac{1}{2 g}\left(u\left[u^{2}+v^{2}-(u)_{\lambda}^{2}-(v)_{\lambda}^{2}\right]\right)_{\lambda_{1}}^{\lambda_{2}} d \phi d p \\
& +c_{2} \int_{p_{1}}^{p_{2}} \frac{1}{2 g}\left(\left[v \cos \phi\left[u^{2}+v^{2}-(u)_{\lambda}^{2}\right]\right]_{\lambda}\right)_{\phi_{1}}^{\phi_{2}} d p \\
& -\left(\frac{1}{2 g}\left[\omega\left[u^{2}+v^{2}-(u)_{\lambda}^{2}-(v)_{\lambda}^{2}\right]\right]_{\lambda \phi}\right)_{p_{1}}^{p_{2}}, \\
& B K_{E}=c_{1} \int_{p_{1}}^{p_{2}} \int_{\phi_{1}}^{\phi_{2}} \frac{1}{2 g}\left(u\left[(u)_{\lambda}^{2}+(v)_{\lambda}^{2}\right]\right)_{\lambda_{1}}^{\lambda_{2}} d \phi d p \\
& +c_{2} \int_{p_{1}}^{p_{2}} \frac{1}{2 g}\left(\left[v \cos \phi\left[(u)_{\lambda}^{2}+\left((v)_{\lambda}^{2}\right)\right]\right]_{\lambda}\right)_{\phi_{1}}^{\phi_{2}} d p \\
& -\left(\frac{1}{2 g}\left[\omega\left[(u)_{\lambda}^{2}+(v)_{\lambda}^{2}\right]\right]_{\lambda \phi}\right)_{p_{1}}^{p_{2}},
\end{aligned}
$$

where $c_{1}=-\left[r\left(\lambda_{2}-\lambda_{1}\right)\left(\sin \phi_{2}-\phi_{1}\right)\right]^{-1}$ and $c_{2}=-\left[r\left(\sin \phi_{2}-\right.\right.$ $\left.\left.\phi_{1}\right)\right]^{-1}$. 
Finally the integrals for $B \Phi Z$ and $B \Phi E$ are

$$
\begin{aligned}
B \Phi Z= & c_{1} \int_{p_{1}}^{p_{2}} \int_{\phi_{1}}^{\phi_{2}} \frac{1}{g}\left([v]_{\lambda}\left([\Phi]_{\lambda}\right)_{\phi}\right)_{\lambda_{1}}^{\lambda_{2}} d \phi d p \\
& +c_{2} \int_{p_{1}}^{p_{2}} \frac{1}{g}\left(\cos \phi[v]_{\lambda}\left([\Phi]_{\lambda}\right)_{\phi}\right)_{\phi_{1}}^{\phi_{2}} d p \\
& -\frac{1}{g}\left(\left[\left([\omega]_{\lambda}\right)_{\phi}\left([\Phi]_{\lambda}\right)_{\phi}\right]_{\lambda \phi}\right)_{p_{1}}^{p_{2}}, \\
B \Phi E= & c_{1} \int_{p_{1}}^{p_{2}} \int_{\phi_{1}}^{\phi_{2}} \frac{1}{g}\left((u)_{\lambda}(\Phi)_{\lambda}\right)_{\lambda_{1}}^{\lambda_{2}} d \phi d p \\
& +c_{2} \int_{p_{1}}^{p_{2}} \frac{1}{g}\left(\left[(v)_{\lambda}(\Phi)_{\lambda}\right] \cos \phi\right)_{\phi_{1}}^{\phi_{2}} \\
& -\frac{1}{g}\left(\left[(\omega)_{\lambda}(\Phi)_{\lambda}\right]_{\lambda \phi}\right)_{p_{1}}^{p_{2}},
\end{aligned}
$$

where $\Phi(=g z)$ is the geopotential.

\section{Acknowledgments}

José Augusto P. Veiga and Tercio Ambrizzi were supported by $\mathrm{CNPq}(150356 / 2011-0)$. Tercio Ambrizzi also has the support from the FAPESP (08/58101-9), CLARIS LPB, and INCLINE/USP.

\section{References}

[1] E. N. Lorenz, “Available potential energy," Tellus, vol. 7, pp. 157167, 1955.

[2] E. N. Lorenz, The Nature and Theory of the General Circulation of the Atmosphere, World Meteorological Organization, 1967.

[3] A. Wiin-Nielsen, "On the intensity of the general circulation of the atmosphere," Reviews of Geophysics, vol. 6, no. 4, pp. 311-323, 1968.

[4] A. H. Oort, "On estimates of the atmospheric energy cycle," Monthly Weather Review, vol. 92, no. 11, pp. 483-493, 1964.

[5] J. P. Peixoto and A. H. Oort, "The annual distribution of atmospheric energy on a planetary scale," Journal of Geophysical Research, vol. 20, no. 15, pp. 2149-2159, 1974.

[6] E. C. Kung and H. Tanaka, "Energetics analysis of the global circulation during the special observation periods of FGGE," Journal of the Atmospheric Sciences, vol. 40, no. 11, pp. 25752592, 1983.

[7] U. Ulbrich and P. Speth, "The global energy cycle of stationary and transient atmospheric waves: results from ECMWF analyses," Meteorology and Atmospheric Physics, vol. 45, no. 3-4, pp. 125-138, 1991.

[8] L. Li, A. P. Ingersoll, X. Jiang et al., "Lorenz energy cycle $\mathrm{f}$ the global atmosphere based on reanalysis datasets," Geophysical Research Letters, vol. 34, Article ID L16813, 2007.

[9] C. A. F. Marques, A. Rocha, and J. Corte-Real, "Global diagnostic energetics of five state-of-the-art climate models," Climate Dynamics, vol. 36, no. 9-10, pp. 1767-1794, 2011.

[10] N.-C. Lau, "The structure and energetics of transient disturbances in the northern hemisphere wintertime circulation," Journal of the Atmospheric Sciences, vol. 36, no. 6, pp. 982-995, 1979.
[11] C. A. Depradine, "Energetics of large-scale motion in the tropics during GATE at $250 \mathrm{mb}$," Monthly Weather Review, vol. 108, no. 7, pp. 886-895, 1980.

[12] S. C. Michaelides, "Limited area energetics of Genoa cyclogenesis," Monthly Weather Review, vol. 115, no. 1, pp. 13-26, 1987.

[13] S. C. Michaelides, "A spatial and temporal energetics analysis of a baroclinic disturbance in the Mediterranean," Monthly Weather Review, vol. 120, no. 7, pp. 1224-1243, 1992.

[14] W. E. Baker and Y. Brin, "A comparison of observed and forecast energetics over North America," Quarterly Journal of the Royal Meteorological Society, vol. 111, no. 468, pp. 641-663, 1985.

[15] T. N. Krishnamurti, M. C. Sinha, B. Jha, and U. C. Mohanty, "A study of South Asian monsoon energetics," Journal of the Atmospheric Sciences, vol. 55, no. 15, pp. 2530-2548, 1998.

[16] T. N. Krishnamurti, S. Pattnaik, L. Stefanova et al., "The hurricane intensity issue," Monthly Weather Review, vol. 113, no. 7, pp. 1886-1912, 2005.

[17] J. A. P. Veiga, A. B. Pezza, I. Simmonds, and P. L. Silva Dias, "An analysis of the environmental energetics associated with the transition of the first South Atlantic hurricane," Geophysical Research Letters, vol. 35, no. 15, Article ID L15806, 2008.

[18] A. B. Pezza, J. A. P. Veiga, I. Simmonds, K. Keay, and M. D. S. Mesquita, "Environmental energetics of an exceptional highlatitude storm," Atmospheric Science Letters, vol. 11, no. 1, pp. 3945, 2010.

[19] A. B. Pezza, A. L. Garde, J. A. P. Veiga, and I. Simmonds, "Large scale features and energetics of the hybrid subtropical low "Duck" over the Tasman Sea," Climate Dynamics, 2013.

[20] G. J. Boer, "Some dynamical consequences of greenhouse gas warming," Atmosphere-Ocean, vol. 33, no. 4, pp. 731-751, 1995.

[21] E. M. Agee, "Trends in cyclone and anticyclone frequency and comparison with periods of warming and cooling over the Northern Hemisphere," Journal of Climate, vol. 4, no. 2, pp. $263-$ 267, 1991.

[22] G. J. McCabe, M. P. Clark, and M. C. Serreze, "Trends in Northern Hemisphere surface cyclone frequency and intensity," Journal of Climate, vol. 14, no. 12, pp. 2763-2768, 2001.

[23] M. C. Serreze, F. Carse, R. G. Barry, and J. C. Rogers, "Icelandic low cyclone activity: climatological features, linkages with the $\mathrm{NAO}$, and relationships with recent changes in the Northern Hemisphere circulation," Journal of Climate, vol. 10, no. 3, pp. 453-464, 1997.

[24] A. B. Pezza and T. Ambrizzi, "Variability of Southern Hmisphere cyclone and anticyclone behavior: further analysis," Journal of Climate, vol. 16, no. 7, pp. 1075-1083, 2003.

[25] A. B. Pezza, I. Simmonds, and J. A. Renwick, "Southern Hemisphere cyclones and anticyclones: recent trends and links with decadal variability in the Pacific Ocean," International Journal of Climatology, vol. 27, no. 11, pp. 1403-1419, 2007.

[26] M. T. Black and A. B. Pezza, "A universal, broad-environment energy conversion signature of explosive cyclones," Geophysical Research Letters, vol. 40, no. 2, pp. 452-457, 2013.

[27] U. Ulbrich, G. C. Leckebusch, J. Grieger et al., "Are greenhouse gas signals of Northern Hemisphere winter extra-tropical cyclone activity dependent on the identification and tracking algorithm?" Meteorologische Zeitschrift, vol. 22, no. 1, pp. 61-68, 2013.

[28] M. Sugi and J. Yoshimura, "Decreasing trend of tropical cyclone frequency in 228-year high-resolution AGCM simulations," Geophysical Research Letters, vol. 39, no. 19, Article ID L19805, 2012. 
[29] K. Oouchi, J. Yoshimura, H. Yoshimura, R. Mizuta, S. Kusunoki, and A. Noda, "Tropical cyclone climatology in a globalwarming climate as simulated in a $20 \mathrm{~km}$-mesh global atmospheric model: frequency and wind intensity analyses," Journal of the Meteorological Society of Japan, vol. 84, no. 2, pp. 259-276, 2006.

[30] C. D. Hoyos, P. A. Agudelo, P. J. Webster, and J. A. Curry, "Deconvolution of the factors contributing to the increase in global hurricane intensity," Science, vol. 312 , no. 5770, pp. 9497, 2006.

[31] D. Hernández-Deckers and J.-S. von Storch, "Energetics responses to increases in greenhouse gas concentration," Journal of Climate, vol. 23, no. 14, pp. 3874-3887, 2010.

[32] D. Hernández-Deckers and J.-S. von Storch, "The energetics response to a warmer climate: relative contributions from the transient and stationary eddies," Earth System Dynamics, vol. 2, no. 1, pp. 105-120, 2011.

[33] G. J. Boer and S. Lambert, "The energy cycle in atmospheric models," Climate Dynamics, vol. 30, no. 4, pp. 371-390, 2008.

[34] B. M. Stevens, M. Giorgetta, M. Esch et al., "Atmospheric component of the MPI-M earth system model: ECHAM6," Journal of Advances in Modeling Earth Systems, vol. 5, no. 2, pp. 146-172, 2012.

[35] T. Crueger, C. Hohenegger, and W. May, “Tropical precipitation and convection changes in the Max Planck institute earth system model (MPI-ESM) in response to $\mathrm{CO}_{2}$ forcing," Journal of Advances in Modeling Earth Systems, vol. 5, pp. 85-97, 2013.

[36] M. A. Giorgetta, J. Jungclaus, C. H. Reick et al., "Climate and carbon cycle changes from 1850 to 2100 in MPI-ESM simulations for the coupled model intercomparison project phase 5," Journal of Advances in Modeling Earth Systems, 2013.

[37] J. H. Jungclaus, H. N. Fischer, H. Haak et al., "Characteristics of the ocean simulations in the Max Planck institute ocean model (MPIOM) the ocean component of the MPI-earth system model," Journal of Advances in Modeling Earth Systems, vol. 5, no. 2, pp. 422-446, 2013.

[38] D. P. van Vuuren, J. Edmonds, M. Kainuma et al., "The representative concentration pathways: an overview, Climatic Change, vol. 109, no. 1, pp. 5-31, 2011.

[39] K. E. Taylor, R. J. Stouffer, and G. A. Meehl, "An overview of CMIP5 and the experiment design," Bulletin of the American Meteorological Society, vol. 93, pp. 485-498, 2012.

[40] D. P. van Vuuren, E. Stehfest, M. G. J. den Elzen et al., "RCP2.6: exploring the possibility to keep global mean temperature increase below $2^{\circ}$ C, 'Climatic Change, vol. 109, no. 1, pp. 95-116, 2011.

[41] A. M. Thomson, K. V. Calvin, S. J. Smith et al., "RCP4.5: a pathway for stabilization of radiative forcing by 2100," Climatic Change, vol. 109, no. 1, pp. 77-94, 2011.

[42] K. Riahi, S. Rao, V. Krey et al., "RCP 8.5-a scenario of comparatively high greenhouse gas emissions," Climatic Change, vol. 109, no. 1, pp. 33-57, 2011.

[43] R. H. Moss, A. Kathy, J. A. Edmonds et al., "The next generation of scenarios for climate change research and assessment," Nature, vol. 463, no. 7282, pp. 747-756, 2010.

[44] H. S. Muench, "On the dynamics of the wintertime stratosphere circulation," Journal of the Atmospheric Sciences, vol. 22, pp. 340-360, 1965. 

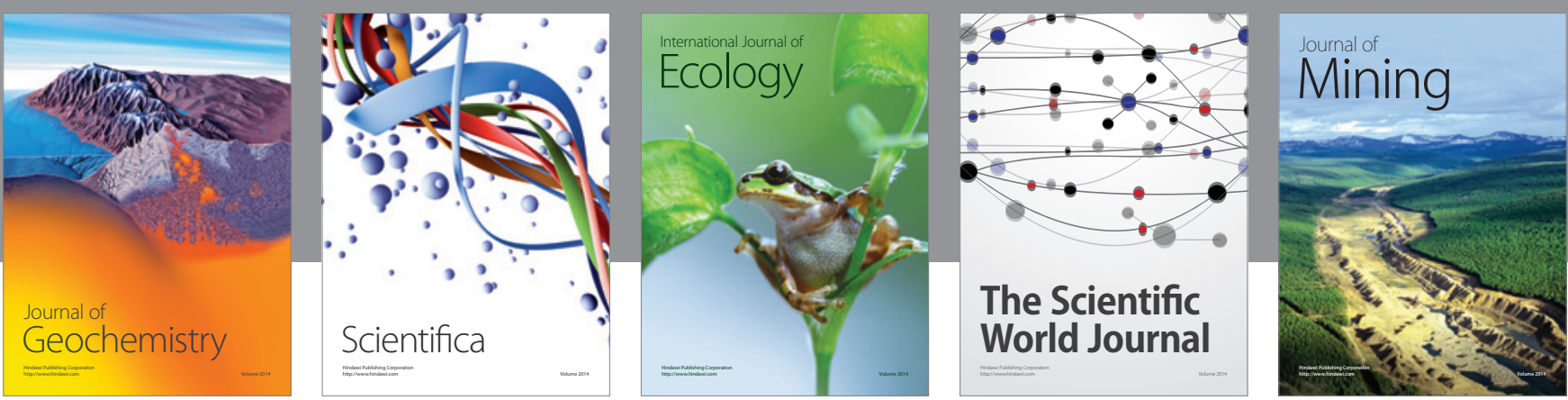

The Scientific World Journal
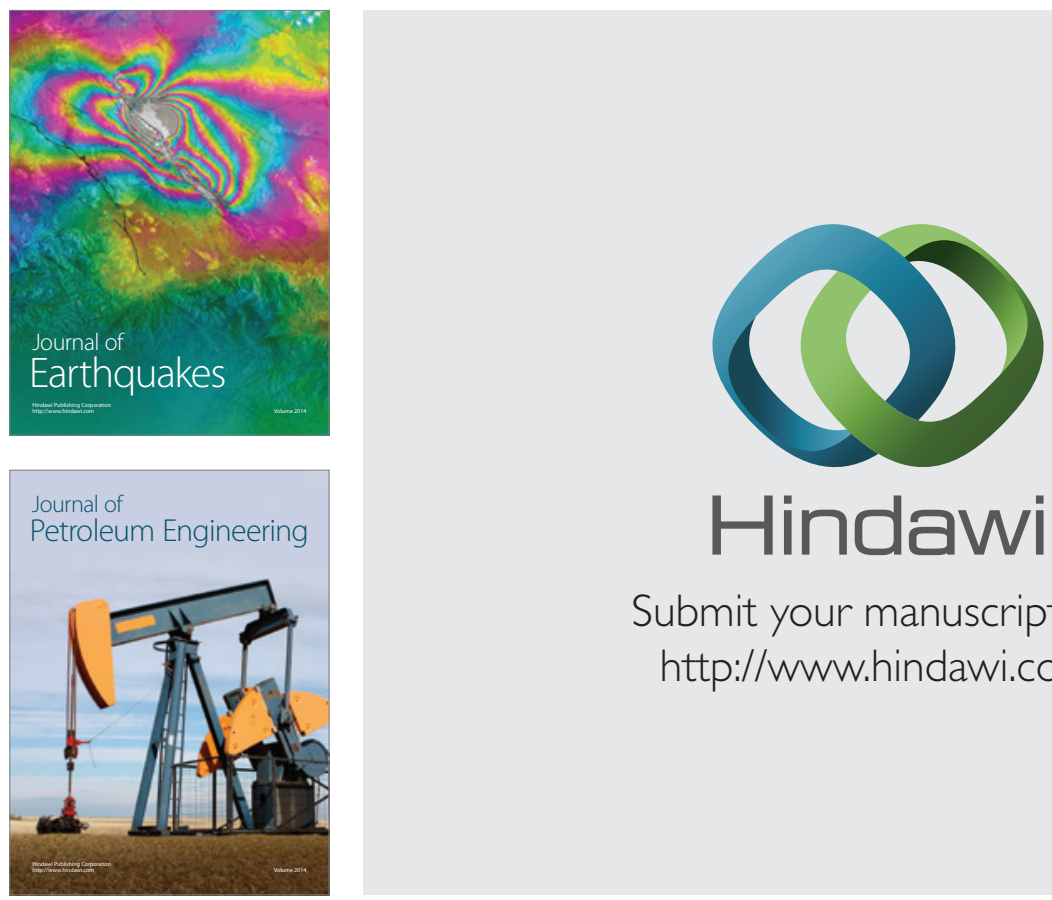

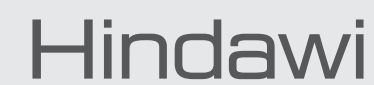

Submit your manuscripts at

http://www.hindawi.com
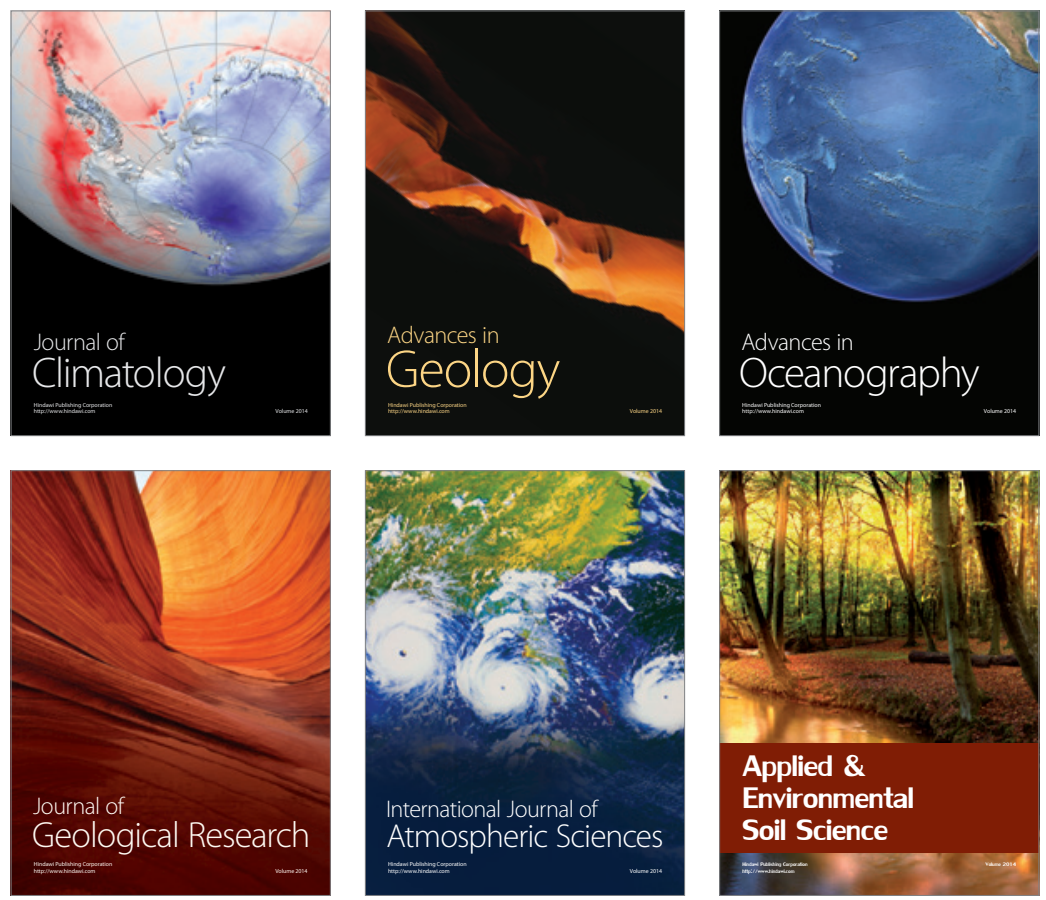
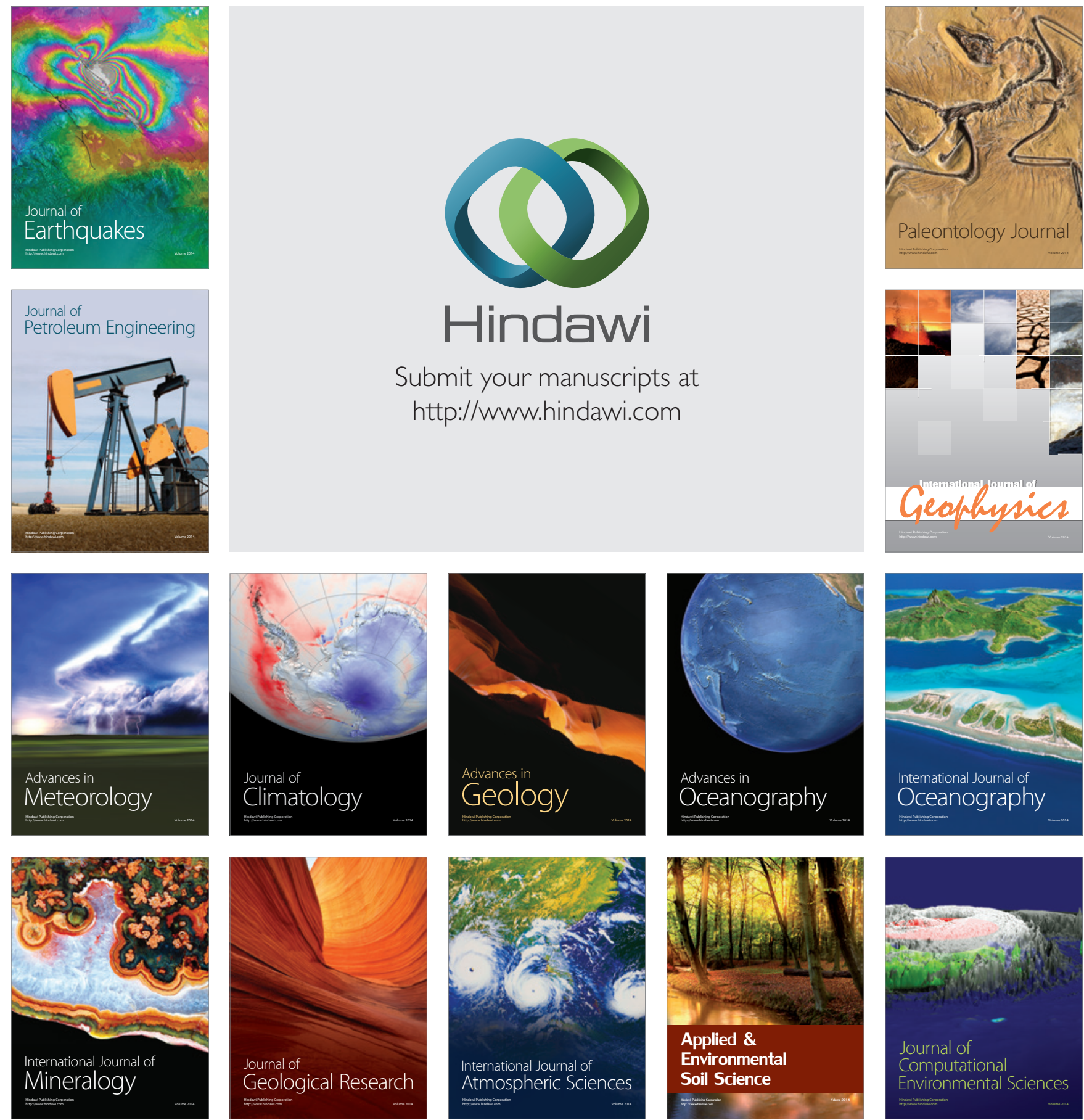